\title{
Severity of Malocclusion and Orthodontic Treatment Needs among 12- to 15-Year-Old School Children of Davangere District, Karnataka, India
}

\author{
KM Shivakumara \\ GN Chandu \\ MD Shafiullac
}

\section{ABSTRACT}

Objectives: To assess the severity of malocclusion and orthodontic treatment needs among 12- to 15-year-old school children of Davangere District, India, by using the Dental Aesthetic Index (DAII).

Methods: A descriptive cross-sectional study was conducted among 180012 - to 15-year-old school children of Davangere District, Karnataka, India. Talukas (administrative units in some states in India) were considered clusters. Schools were selected using simple random sampling procedures. The 300 study subjects were selected using systematic random sampling procedures. Data consisting of DAl components were recorded pro forma. The collected data were subjected to statistical analysis. The Chi-square test $\left(\mathrm{X}^{2}\right)$ was used to compare malocclusion severity. The analysis of variance (ANOVA) test was used to compare the changes in DAI scores and the mean DAl scores between age groups. The $Z$ test was used to compare mean DAl scores between the 2 sexes and between children residing in urban and rural areas.

Results: Of the 1800 school children examined, 899 (49.9\%) were boys and 901 (50.1\%) were girls. Most of the children (79.9\%) had DAl scores $\leq 25$ with no or minor malocclusion requiring no or little treatment, $15.4 \%$ had DAl scores of 26-30 with definite malocclusion requiring elective treatment, $4.2 \%$ had DAI scores of 31-35 with severe malocclusion requiring highly desirable treatment, and $0.5 \%$ had DAI scores $\geq 36$ with handicapping malocclusion requiring mandatory treatment.

Conclusions: The majority of the children in our study (79.9\%) required no or little treatment; $20.1 \%$ had definite malocclusion requiring definite orthodontic treatment. (Eur J Dent 2010;4:298307)

Key words: Malocclusion; Dental Aesthetic Index; Treatment needs.

- a Assistant Professor, Department of Public Health Dentistry, Sharad Pawar Dental College and Hospital, Datta Meghe Institute of Medical Sciences University, Maharashtra, India.

b Professor and Head, Department of Public Health Dentistry, College of Dental Sciences, Davangere, Karnataka, India.

Professor and Head, Department of Public Health Dentistry, Vishnu Dental College and Hospital, Bhimavaram, Andhrapradesh, India.
- Corresponding author:

KM Shivakumar

Department of Public Health Dentistry, Sharad Pawar Dental College and Hospital,

Datta Meghe Institute of Medical Sciences University, Sawangi (Meghe), Wardha - 442004 ,

Maharashtra, India.

Phone: + 919422393103

Fax: +917152241711

E-mail: kmshivakumardarediffmail.com 


\section{INTRODUCTION}

Increased concern about dental appearance during childhood and adolescence to early adulthood has been observed. The public equates good dental appearance with success in many pursuits. In general, societal forces define the norms for acceptable, normal, and attractive physical appearance. ${ }^{1}$ The word malocclusion literally means "bad bite".,3 Malocclusion can be defined as an occlusion in which there is a malrelationship between the arches in any of the planes of spaces or in which there are anomalies in tooth position beyond normal limits. ${ }^{3}$ An individual with malocclusion might develop a feeling of shame about their dental appearance and may feel shy in social situations or lose career opportunities. ${ }^{4}$

Malocclusion has not been thoroughly investigated because the related pain and misery are seldom acute. However, malocclusion has a large impact on both individuals and society in terms of discomfort, quality of life, and social and functional limitations. ${ }^{2,5,6}$ Genetic, environmental, or a combination of both factors, along with various local factors such as adverse oral habits and anomalies in number, form, and developmental position of teeth can cause malocclusion. ${ }^{7}$ Malocclusion has been shown to affect periodontal health, increase the prevalence of dental caries, and cause temporomandibular joint problems. ${ }^{3}$ Hence, it is important to determine the prevalence of malocclusion and its occurrence and distribution in a community. The prevalence of malocclusion varies from country to country and between different age and sex groups; its prevalence in India is $20 \%-43 \%^{2,8}$

The decision to pursue orthodontic treatment is influenced by the desire to look attractive, selfperception of dental appearance, self-esteem, gender, age, and peer-group norms. ${ }^{9-11}$ The major benefits of orthodontic treatment include improvement of physical function, prevention of tissue damage, and correction of aesthetic components. ${ }^{12}$ Considering these factors, the Dental Aesthetic Index (DAI), which is recommended by the World Health Organization (WHO) as a rapid and relatively simple method of assessing dentofacial anomalies, was developed. ${ }^{13-19}$ The DAl is a cross-cultural index that focuses on socially defined standards for dental aesthetics ${ }^{20}$ and was designed for use in permanent dentition. ${ }^{21,22}$ Very few studies have assessed the severity of malocclusion and orthodontic treatment needs in India.

The aim of this study was to assess the severity of malocclusion and orthodontic treatment needs in 12- to 15-year-old school children of Davangere District, Karnataka, India.

\section{MATERIALS AND METHODS}

A descriptive cross-sectional study was conducted among 12- to 15-year-old school children (mean age, 13.8 \pm 1.1 years) of Davangere District, Karnataka, India. All school children included in the study were between a minimum age of 12.1 years and a maximum age of 15.4 years. A pilot study was carried out to determine the feasibility of the study. The time required for examination of each subject and the practical application of the DAl was assessed during the examination. According to the pilot study, the prevalence of definite malocclusion was $20 \%$, and a final study sample of 1800 was determined. Before the start of the study, ethical clearance was obtained from the Institutional Ethical Clearance Committee of College of Dental Sciences, Davangere. Official permission was obtained from the Deputy Director of Public Instruction (DDPI), Davangere. The study was conducted over a period of 1 year (July 2005 to June 2006).

\section{Examiner training and calibration}

Oral examinations were performed by two trained and calibrated examiners. Before the survey, both the examiners and the scribes participated in a 2-day training and clinical calibration exercise in the department. Following this training, $10 \%$ of the children were examined by each of the 2 investigators to assess interexaminer reliability; Kappa values of 0.87 and 0.88 were found, respectively. Intraexaminer reproducibility was assessed by re-examination of $10 \%$ of the samples. There was good agreement between the examinations by the same examiner. During the survey at the end of the day, ten study subjects were re-examined by each examiner to verify intraexaminer consistency.

Davangere District has 6 Talukas ladministrative units in some states in India), considered clusters for the purposes of this study. The study sample was taken from all 6 clusters Icluster 
sampling). Each cluster was stratified into urban and rural areas. From each stratum, schools were selected proportionately by using a simple random sampling procedure. In each cluster, 300 students were selected by using a systematic random sampling technique in which 100 students were examined in the urban area and 200 students were examined in the rural areas; the required numbers of study subjects were selected by using a systematic random sampling procedure. The same procedure was adopted for the other strata as well. Interview and examination of a single study subject took 3 to 4 minutes. Children who previously or currently had orthodontic treatment including those on interceptive orthodontics were excluded from the study. A specially designed survey proforma was prepared with the help of the WHO Oral Health Assessment Form. ${ }^{13}$

\section{Examination procedure}

Malocclusion examinations were conducted according to the DAl as described by the WHO Oral Health Survey Basic Methods ${ }^{13}$ by using a community periodontal index (CPI) probe and plane mouth mirror. Type-III clinical examination as recommended by American Dental Association (ADA) specifications was followed. Sufficient numbers of instruments were carried to the examination location to prevent interruption during the study. Korsolex chemical solution was used for cold sterilization. After each examination day, all instruments were autoclaved. The school children requiring treatment were referred to the College of Dental Sciences, Davangere. Recorded data were transferred from the pre-coded survey proforma to a computer. The statistical average, mean, and standard deviation were employed to represent the different measurements.

\section{Statistical analysis}

The Chi-square test $\left(X^{2}\right)$ was used to compare malocclusion prevalence between different groups. The analysis of variance (ANOVA) test was used to compare the changes in DAl scores and the mean DAl scores between the various age groups. The $Z$ test was used to compare the mean DAl scores between sex groups and between residence types. A probability value of 0.05 or less was set as the significance level. The data were analyzed using the Statistical Package for Social Sciences (SPSS).

\section{RESULTS}

The study population consisted of 1800 school children 12 to 15 years of age in Davangere District. Of the total sample size, 899 (49.9\%) were boys and 901 (50.1\%) were girls. A total of 600 $(33.4 \%)$ urban and $1200(66.6 \%)$ rural school children were examined (Table 1).

Of the 1800 examined school children, 1608 $(89.3 \%)$ had no missing anterior teeth while 192 $(10.7 \%)$ had 1 or more missing anterior teeth. Among the 899 examined boys, 793 (88.2\%) had no missing anterior teeth, and $106(11.8 \%)$ had 1 or more missing anterior teeth. Among the 901 examined girls, 815 (90.5\%) had no missing anterior teeth, and 86 (9.5\%) had 1 or more missing anterior teeth. This difference between boys and girls was found to be statistically significant $\left(X^{2}=8.44\right.$, **P<.004, S). A total of $1103(61.3 \%)$ school children had no incisal segment crowding and 697 (38.7\%) had 1- or 2-segment crowding. No statistically significant differences in segment crowding were observed in the study group $\left(X^{2}=0.21, P=0.90\right.$, NS). A total of 1518 (84.3\%) school children had no incisal segment spacing and 282 (15.7\%) had 1 - or 2-segment spacing. No statistically significant differences were observed in the study group $\left(X^{2}=0.65, P=0.72, N S\right)$. Of 1800 school children ex-

Table 1. Demographic characteristics of the study population

\begin{tabular}{|c|c|c|c|c|c|}
\hline \multirow[b]{2}{*}{ Age in years } & \multicolumn{2}{|c|}{ Sex } & \multirow[b]{2}{*}{ Total n $(\%)$} & \multirow[b]{2}{*}{ Urban n (\%) } & \multirow[b]{2}{*}{ Rural n (\%) } \\
\hline & Boys $\mathrm{n}(\%)$ & Girls n (\%) & & & \\
\hline 12 & 222 (12.3) & $227(12.6)$ & 449 (24.9) & $160(35.6)$ & 289 (64.4) \\
\hline 13 & $223(12.4)$ & $213(11.8)$ & 436 (24.2) & 144 (33.0) & $292(67.0)$ \\
\hline 14 & 227 (12.6) & 223 (12.4) & $450(25.0)$ & 144 (32.0) & $306(68.0)$ \\
\hline 15 & 227 (12.6) & 238 (13.3) & 465 (25.9) & 152 (32.7) & 313 (67.3) \\
\hline Total & 899 (49.9) & $901(50.1)$ & $1800(100)$ & 600 (33.4) & $1200(66.6)$ \\
\hline
\end{tabular}


amined, 1524 (84.7\%) had no midline diastema and 176 (15.3\%) had diastema of $~ 1-3 \mathrm{~mm}$. Statistically significant results were observed between boys and girls ( $\left.X^{2}=10.7, * P<.05, S\right)$. No statistically significant differences were observed in the study group $\left(X^{2}=2.19, P=0.54, N S\right)$ in maxillary, and mandibular anterior teeth irregularity $\left(X^{2}=0.88, P=0.64\right.$, NS) (Table 2).

In the present study, 1672 (93.3\%) school children had an anterior maxillary overjet of 0 to 2 $\mathrm{mm}$, and $120(6.7 \%)$ had an overjet of $>2 \mathrm{~mm}$. Of the boys, 827 (92.8\%) had an anterior maxillary overjet of 0-2 mm, and $67(7.2 \%)$ had an overjet of $>2 \mathrm{~mm}$. Of the girls, $845(94.1 \%)$ had an anterior maxillary overjet of 0-2 mm, and 53 (5.9\%) had an overjet of $>2 \mathrm{~mm}$. However, no statistically significant differences were observed between boys and girls ( $X^{2}=8.78, P=0.07$, NS). Of the 1800 examined school children, 1792 (99.6\%) had no mandibular overjet and $8(0.4 \%)$ had a mandibular overjet of 1-2 $\mathrm{mm}$. No statistically significant differences were observed between boys and girls $\left(X^{2}=0.51\right.$, $\mathrm{P}=0.48$, NS). Of the 1800 examined school children, 1757 (97.6\%) had no anterior open bite and $43(2.4 \%)$ had an anterior open bite of $1-3 \mathrm{~mm}$. Of the 899 examined boys, 879 (97.8\%) had no anterior open bite and $20(2.2 \%)$ had an anterior open bite of $1-3 \mathrm{~mm}\left(X^{2}=0.21, P=0.65, N S\right)$. Of the 1800 examined school children, 1622 (90.1\%) had normal molar relationship, 94 (5.2\%) had half-cusp deviation, and 84 (4.7\%) had full-cusp deviation. However, no statistically significant differences were observed in the study group $\left(X^{2}=3.34, P=0.19\right.$, NS) (Table 2).

In the present study, the distribution of DAI scores and orthodontic treatment needs showed, 1438 (79.9\%) had DAl scores $\leq 25$ with no abnormality or little malocclusion requiring no or slight treatment, $278(15.4 \%)$ had DAl scores of 26-30 with definite malocclusion requiring elective orthodontic treatment, 75 (4.2\%) had DAl scores of 31-35 with severe type of malocclusion requiring highly desirable orthodontic treatment, 9 (0.5\%) had DAl scores $\geq 36$ with very severe or handicapping malocclusion requiring mandatory type of orthodontic treatment. The mean DAl score was

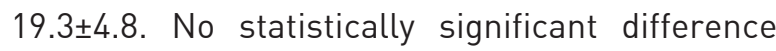
was observed among the study group as well as mean DAl score respectively $\left(X^{2}=9.74, P=0.14, N S\right.$; ANOVA, $F=0.51, P=0.67, \mathrm{NS}$ ) (Table 3).
Of the 899 boys examined, 720 (80.1\%) had DAl scores $\leq 25,143(15.9 \%)$ had DAl scores of 26-30, $32(3.6 \%)$ had DAl scores of $31-35,4(0.4 \%)$ had DAl scores $\geq 36$; the mean DAl score was $19.7 \pm 5.1$. Of 901 girls examined, $718(79.6 \%)$ had DAl scores $\leq$ 25,135 (15.0\%) had DAl scores of 26-30, 43 (4.8\%) had DAl scores of $31-35,5(0.6 \%)$ had DAl scores $\geq 36$; the mean DAl score was $19.8 \pm 5$.0. No statistically significant difference was found between the 2 sexes and mean DAl scores respectively. $\left(X^{2}=1.95, P=0.38, N S ; Z=0.45, P=0.66, N S\right)$ (Table 4).

The DAl score and type of residence lurban/ rural) had a significant relationship. In the present study, 445 (74.2\%) had DAl scores $\leq 25,119$ $(19.8 \%)$ had DAl scores of $26-30,30(5.0 \%)$ had DAl scores of $31-35,6(1.0 \%)$ had DAl scores $\geq 36$; the mean DAl score was $20.5 \pm 5.5$. Of 1200 rural school children examined, 993 (82.7\%) had DAl scores $\leq 25,159(13.2 \%)$ had DAl scores of 26-30, $45(3.8 \%)$ had DAl scores of $31-35,3(0.3 \%)$ had DAl scores $\geq 36$; the mean DAl score was $19.3 \pm 4.8$. The difference was found to be highly statistically significant among the type of residence as well as for mean DAl scores $\left(X^{2}=18.3, * * * P<.001, S ; Z=4.2\right.$, *** $\mathrm{P}<.001, \mathrm{~S})$ (Table 5).

In the present study, 1438 (79.9\%) school children had DAl scores $\leq 25$ and no or little malocclusion requiring no or slight orthodontic treatment, 278 (15.4\%) had DAl scores of 26-30 with definite malocclusion requiring elective orthodontic treatment, 75 (4.2\%) had DAl scores of 31-35 with severe malocclusion requiring highly desirable orthodontic treatment, and $9(0.5 \%)$ had DAl scores $\geq$ 36 with very severe or handicapping malocclusion requiring mandatory orthodontic treatment (Table 6).

\section{DISCUSSION}

Missing anterior teeth

The number of missing permanent incisor, canine and premolar teeth in the upper and lower arches was recorded. A history of all missing anterior teeth was obtained to determine whether extractions were performed for aesthetic reasons. Teeth were not recorded as missing if spaces were closed, if a primary tooth was still in position and its successor had not yet erupted, or if a missing incisor, canine, or premolar tooth had been replaced by a fixed prosthesis. ${ }^{13}$ In the current study, $10.7 \%$ of the study population had 1 or 
more missing anterior teeth either in the maxilla or in the mandible, the differences of which between boys and girls were statistically significant $(P<.004)$. Results of previous studies ${ }^{23-26}$ showed similar trends of missing teeth in boys and girls.

Incisal segment crowding

Crowding of the incisal segment is a condition in which the available space between the right and left canine teeth is insufficient to accommodate all four incisors in normal alignment; as a result, the teeth may be rotated or displaced out of the arch. ${ }^{13}$ The slight increase in anterior arch dimension during normal development is not sufficient to overcome moderate to severe discrepancies under these conditions. Crowding is likely to persist in permanent dentition. Crowding of the incisal segment affects half of all children in mixed dentition, worsens in the adolescent years as the permanent

Table 2. Distribution of DAl components.

\begin{tabular}{|c|c|c|c|c|}
\hline DAl components & Boys n (\%) & Girls n (\%) & Total n (\%) & \\
\hline \multicolumn{5}{|c|}{ Missing anterior teeth } \\
\hline 0 & 793 (88.2) & 815 (90.5) & 1608 (89.3) & $X^{2}=8.44$ \\
\hline $1-3$ teeth & 106 (11.8) & 86 (9.5) & $192(10.7)$ & ${ }^{* *} \mathrm{P}<.004, \mathrm{~S}$ \\
\hline \multicolumn{5}{|c|}{ Incisal segment crowding } \\
\hline 0 & $555(61.7)$ & $548(60.8)$ & $1103(61.3)$ & $X^{2}=0.21$ \\
\hline $1-2 \mathrm{~mm}$ & 344 (38.3) & 353 (39.2) & $697(38.7)$ & $\mathrm{P}=0.90, \mathrm{NS}$ \\
\hline \multicolumn{5}{|c|}{ Incisal segment spacing } \\
\hline 0 & $764(85.0)$ & 754 (83.7) & 1518 (84.3) & $X^{2}=0.65$ \\
\hline $1-2 \mathrm{~mm}$ & $135(15.0)$ & $147(16.3)$ & $282(15.7)$ & $\mathrm{P}=0.72, \mathrm{NS}$ \\
\hline \multicolumn{5}{|l|}{ Midline Diastema } \\
\hline 0 & $779(86.7)$ & $745(82.7)$ & $1524(84.7)$ & $X^{2}=10.7$ \\
\hline $1-\geq 3 \mathrm{~mm}$ & 120 (13.3) & $156(17.3)$ & $176(15.3)$ & ${ }^{* *} \mathrm{P}<.01, \mathrm{~S}$ \\
\hline \multicolumn{5}{|c|}{ Maxillary anterior irregularity (mm) } \\
\hline 0 & $693(77.1)$ & $693(76.9)$ & $1386(77.0)$ & $X^{2}=2.19$ \\
\hline$>1 \mathrm{~mm}$ & 206 (22.9) & $208(23.1)$ & $414(23.0)$ & $\mathrm{P}=0.54, \mathrm{NS}$ \\
\hline \multicolumn{5}{|c|}{ Mandibular anterior irregularity $(\mathrm{mm})$} \\
\hline 0 & $744(82.8)$ & $731(81.1)$ & 1475 (81.9) & $X^{2}=0.88$ \\
\hline $1-\leq 3 \mathrm{~mm}$ & 155 (17.2) & $170(18.9)$ & $325(18.1)$ & $P=0.64, N S$ \\
\hline \multicolumn{5}{|c|}{ Anterior maxillary overjet (mm) } \\
\hline $0-2 \mathrm{~mm}$ & $827(92.8)$ & $845(94.1)$ & 1672 (93.3) & $X^{2}=8.78$ \\
\hline$>2 \mathrm{~mm}$ & $67(7.2)$ & $53(5.9)$ & $120(6.7)$ & $P=0.07, N S$ \\
\hline \multicolumn{5}{|c|}{ Anterior mandibular overjet (mm) } \\
\hline 0 & $894(99.5)$ & $898(99.7)$ & $1792(99.6)$ & $X^{2}=0.51$ \\
\hline$\geq 1 \mathrm{~mm}$ & $5(0.5)$ & $3(0.3)$ & $8(0.4)$ & $P=0.48, N S$ \\
\hline \multicolumn{5}{|c|}{ Vertical anterior openbite (mm) } \\
\hline 0 & $879(97.8)$ & $878(97.4)$ & $1757(97.6)$ & $X^{2}=0.21$ \\
\hline$\geq 1 \mathrm{~mm}$ & $20(2.2)$ & $23(2.6)$ & $43(2.4)$ & $P=0.65, N S$ \\
\hline \multicolumn{5}{|c|}{ Antero-posterior molar relation (mm) } \\
\hline Normal & $801(89.1)$ & $821(91.1)$ & $1622(90.1)$ & $X^{2}=3.34$ \\
\hline Half cusp deviation & $48(5.3)$ & $46(5.1)$ & $94(5.2)$ & $P=0.19, N S$ \\
\hline Full cusp deviation & $50(5.6)$ & 34 (3.8) & $84(4.7)$ & \\
\hline
\end{tabular}

$\mathrm{X}^{2}=$ Chi-square test,${ }^{*} \mathrm{P}<.05$ Significant (S) , P>.05 Not Significant (NS) 
teeth erupt, and continues to increase as the child ages ${ }^{27} \mathrm{~A}$ study by Otuyemi et al ${ }^{28}$ showed a similar pattern of incisal segment crowding, but results of other studies 2,24,29 showed higher prevalence. According to Thilander et al, ${ }^{30}$ females show more crowding. The reason for this difference could be due to the racial or genetic composition of the study groups as well as abnormal tooth position, which commonly leads to crowding of teeth.

\section{Incisal segment spacing}

Incisal segment spacing is a condition in which the amount of space available between the right and left canine teeth exceeds that required to ac- commodate all four incisors in normal alignment. If 1 or more incisor teeth in the current study had proximal surfaces lacking interdental contact, the segment was recorded as having space. Both the upper and lower incisal segments were examined for spacing. ${ }^{13}$ In the present study, $15.7 \%$ of the study population had incisal segment spacing either in one or both arches. One of the features of normal occlusion is arch continuity as expressed by proximal contact between all teeth in each dental arch. Factors such as mesial drift, slope of occluding cusp, transseptal fibers, and occlusal force direction can contribute to maintenance

Table 3. Age wise distribution of DAl scores and orthodontic treatment needs.

\begin{tabular}{|c|c|c|c|c|c|c|}
\hline \multirow[b]{3}{*}{ Age } & \multicolumn{6}{|c|}{ DAI Scores } \\
\hline & & $\leq 25 \mathrm{n}(\%)$ & $26-30$ n $(\%)$ & $31-35$ n $(\%)$ & $\geq 36$ n $(\%)$ & \\
\hline & $\mathrm{n}(\%)$ & No/slight need & Elective treatment & Highly desirable & $\begin{array}{l}\text { Mandatory } \\
\text { treatment }\end{array}$ & Mean $\pm S D$ \\
\hline 12 & 449 (24.9) & $362(80.7)$ & $59(13.1)$ & $23(5.1)$ & $5(1.1)$ & $19.9 \pm 5.4$ \\
\hline 13 & 436 (24.2) & $345(79.2)$ & $66(15.1)$ & $25(5.7)$ & $0(0)$ & $19.7 \pm 5.0$ \\
\hline 14 & $450(25.0)$ & $361(80.2)$ & 76 (16.9) & $12(2.7)$ & $1(0.2)$ & $19.5 \pm 4.8$ \\
\hline 15 & 465 (25.9) & $370(79.6)$ & $77(16.6)$ & 15 (3.2) & $3(0.6)$ & $19.8 \pm 5.0$ \\
\hline Total & $1800(100)$ & 1438 (79.9) & 278 (15.4) & 75 (4.2) & $9(0.5)$ & $19.3 \pm 4.8$ \\
\hline
\end{tabular}

$X^{2}=9.74, P=0.14, N S \quad d f=6$ Mean DAl, ANOVA, $F=0.51, P=0.67$ NS

Table 4. Gender wise distribution of DAl scores orthodontic treatment needs.

\section{DAl scores}

\begin{tabular}{|c|c|c|c|c|c|c|}
\hline Gender & $\mathrm{n}(\%)$ & $\leq 25 \mathrm{n}(\%)$ & $26-30 \mathrm{n}(\%)$ & $31-35 \mathrm{n}(\%)$ & $\geq 36 \mathrm{n}(\%)$ & Mean $\pm S D$ \\
\hline Boys & 899 (49.9) & $720(80.1)$ & 143 (15.9) & $32(3.6)$ & $4(0.4)$ & $19.7 \pm 5.1$ \\
\hline Girls & 901 (50.1) & 718 (79.6) & $135(15.0)$ & $43(4.8)$ & $5(0.6)$ & $19.8 \pm 5.0$ \\
\hline Total & $1800(100)$ & 1438 (79.9) & 278 (15.4) & 75 (4.2) & $9(0.5)$ & $19.3 \pm 4.8$ \\
\hline
\end{tabular}

$X^{2}=1.95, P=0.38, N S, d f=2 ; Z=0.45, P=0.66, N S$

Table 5. DAl scores and status of residence of study population.

\begin{tabular}{|c|c|c|c|c|c|c|}
\hline \multirow[b]{2}{*}{ Urban/ Rural } & \multicolumn{6}{|c|}{ DAl scores } \\
\hline & n $(\%)$ & $\leq 25 \mathrm{n}(\%)$ & $26-30 \mathrm{n}(\%)$ & $31-35$ n (\%) & $\geq 36 \mathrm{n}(\%)$ & Mean $\pm S D$ \\
\hline Urban & $600(33.4)$ & 445 (74.2) & $119(19.8)$ & $30(5.0)$ & $6(1.0)$ & $20.5 \pm 5.5$ \\
\hline Rural & $1200(66.6)$ & 993 (82.7) & 159 (13.2) & 45 (3.8) & $3(0.3)$ & $19.3 \pm 4.8$ \\
\hline Total & $1800(100)$ & 1438 (79.9) & 278 (15.4) & 75 (4.2) & $9(0.5)$ & $19.3 \pm 4.9$ \\
\hline
\end{tabular}

$X^{2}=18.3,{ }^{* * *} P<.001 S ; Z=4.2, * * * P<.001 \mathrm{~S}$

Table 6. Prevalence of malocclusion and orthodontic treatment needs of study population.

\begin{tabular}{l|ccc}
\hline $\mathbf{n}(\%)$ & DAl scores & Severity of malocclusion & Treatment need \\
\hline $1438(79.9)$ & $\leq 25$ & No abnormality or minor malocclusion & No or slight need \\
$278(15.4)$ & $26-30$ & Definite malocclusion & Elective \\
$75(4.2)$ & $31-35$ & Severe malocclusion & Highly desirable \\
$9(0.5)$ & $\geq 36$ & Very severe or handicapping & Mandatory \\
\hline
\end{tabular}


of this continuity. ${ }^{31}$ Results of previous studies ${ }^{24,28}$ showed higher prevalence of missing incisal segments. This difference could be attributed to missing or undersized lateral incisors; parafunctional habits such as thumb sucking, mouth breathing, and tongue thrusting; rotated incisors; anodontia; macroglossia; dento-alveolar discrepancies; and true tooth size and jaw size discrepancies. In a study by Gauba et al, $3210.3 \%$ of school children had malocclusion due to abnormal oral habits.

\section{Midline diastema}

Midline diastema is defined as the space, in millimeters, between the two permanent maxillary incisors at the normal position of the contact points. ${ }^{13}$ Of the 1800 school children examined in the current study, $15.3 \%$ had midline diastema $(\geq 1 \mathrm{~mm})$, results of which were significant between boys and girls $\left(X^{2}=10.7, * * P<.01, S\right)$. In the developing dentition of children ages 8 to 12 years, the presence of diastema is regarded as a normal phenomenon ("ugly duckling stage").3,31 In the absence of a deep overbite, these spaces normally close spontaneously. ${ }^{31}$ Results of previous studies $^{24,28}$ showed higher prevalence of midline diastema. This difference could be due to that the children may have had different parafunctional habits, deleterious oral habits, mouth breathing, tongue thrusting, microdontia, abnormal labial frenum, dilacerations of the central incisors, or dento-alveolar discrepancies of the jaws. Girls showed a higher incidence $(17.3 \%)$ compared to boys $(13.3 \%)$, the difference of which was statistically significant $\left(X^{2}=10.7, * * P<.01, S\right)$. Similar results were observed in a study ${ }^{33}$ for midline diastema in girls.

\section{Maxillary anterior irregularity}

Maxillary anterior irregularity may be either rotations out of or displacements from normal alignment. Incisors in the maxillary arch should be examined for identification of the greatest irregularity. Irregularities may occur with or without crowding. In the current study, if sufficient space was available for all 4 incisors in normal alignment but some teeth were rotated or displaced, the largest irregularity was recorded. ${ }^{13}$ Of the 1800 examined school children, $23.0 \%$ had a maxillary anterior irregularity of $\geq 1 \mathrm{~mm}$. Results of other studies ${ }^{25,28}$ showed a higher incidence of anterior maxillary irregularities. The difference could be attributed to crowding predisposition caused by genetic differences and environmental factors.

Mandibular anterior irregularity

Mandibular anterior irregularity may be either rotations out of or displacements from normal alignment. Incisors in the mandibular arch should be examined for identification of the greatest irregularity. ${ }^{13}$ In the present study, $18.1 \%$ of the study population had a mandibular anterior irregularity of $\geq 1 \mathrm{~mm}$. Results of other studies $21,22,24,26$ showed a higher incidence of large anterior mandibular irregularities. This disparity could be due to differences in racial or genetic composition of the study groups. In the current study, the size of the irregularities ranged from 1 to $4 \mathrm{~mm}$ and irregularities of $\leq 3 \mathrm{~mm}$ were more prevalent in the maxilla than in the mandible. This difference could be due to variation in development and maturation of the arches, and the children may have had different deleterious oral habits, mouth breathing, tongue thrusting, or dento-alveolar discrepancies of the jaws.

\section{Anterior maxillary overjet}

Anterior maxillary overjet is a measurement of the horizontal relationship of the incisors with the teeth in centric occlusion. The distance from the labial-incisal edge of the most prominent upper incisor to the labial surface of the corresponding lower incisor was measured. ${ }^{13}$ Results of the current study indicated that $93.3 \%$ of the subjects presented with a normal maxillary overjet of 0-2 $\mathrm{mm}$ and $6.7 \%$ presented with an anterior maxillary overjet of $>2 \mathrm{~mm}$. The results of the present study correlated with the studies by Johnson and Harkness, ${ }^{24}$ Brunelle et al, ${ }^{34}$ and Al-Emran et al. ${ }^{35}$ However, a higher incidence was observed in both boys and girls in studies conducted by Esa et al ${ }^{25}$ and Harrison and Davis. ${ }^{36}$ This could be due to differences in genetic and environmental factors, and there also may be differences in geographical location and population groups by gender.

\section{Anterior mandibular overjet}

Anterior mandibular overjet was recorded when any lower incisor protruded anteriorly or labially to the opposing upper incisor, i.e., is in crossbite. Mandibular overjet was not recorded 
if a lower incisor was rotated so that one part of the incisal edge was in crossbite (i.e., labial to the upper incisor). ${ }^{13}$ Anterior mandibular overjet indicates a class III malocclusion or anterior crossbite. Anterior mandibular overjets in the current study ranged from 1 to $2 \mathrm{~mm}$, and $0.4 \%$ school children had a mandibular overjet of $\geq 1 \mathrm{~mm}$ suggesting a great treatment need. A higher incidence was observed for boys and girls in studies conducted by Onyeaso, ${ }^{22}$ Otuyemi et al, ${ }^{28}$ and Burden et al. ${ }^{37} \mathrm{~A}$ study conducted by Hill ${ }^{38}$ showed that $5.9 \%$ of 12 -year-old children and $5.4 \%$ of 15 -yearold children had mandibular overjet. These differences could be attributed to genetic predisposition, variation in growth, or disproportion in the dento-alveolar width.

\section{Vertical anterior open bite}

Anterior open bite is a lack of vertical overlap between any of the opposing pairs of incisors lopen bite)..$^{13}$ This condition reflects discrepancies in the vertical plane of space. As a child grows, it is likely that malocclusion in the vertical plane of space is related to skeletal jaw proportions and not just to displacement of the teeth. ${ }^{27}$ In the present study, $2.4 \%$ of children presented with vertical anterior open bite ranging from 1 to $3 \mathrm{~mm}$. Similar results were observed by Hill. ${ }^{38}$ The studies by Nganga et $\mathrm{al}^{39}$ and Garcia et a ${ }^{29}$ showed a higher incidence of vertical anterior open bite. These differences could be due to variation in development and maturation of the arches, or the children may have had different deleterious oral habits, mouth breathing, tongue thrusting, or dento-alveolar discrepancies of the jaws. No statistically significant differences were observed between boys and girls in any of the above studies.

\section{Anteroposterior molar relationship}

The anteroposterior molar relationship is most often based on the relationship between the permanent upper and lower first molars. The right and the left sides were assessed with the teeth in occlusion and only the largest deviation from the normal relationship (Angle Class I) was recorded. ${ }^{13}$ In the current study, $90.1 \%$ of the school children had normal anteroposterior molar relationships, i.e., Class I. Of the affected group, $5.2 \%$ had half-cusp deviation and $4.7 \%$ had full-cusp deviation. Similar results were observed in studies by
Sureshbabu et $\mathrm{al}^{2}$ and Otuyemi et $a{ }^{28}$

\section{DAl score distribution}

In the present study, $79.9 \%$ of school children had DAl scores $\leq 25$ with no or minor malocclusion requiring no or slight orthodontic treatment, $15.4 \%$ had DAl scores of 26-30 with definite malocclusion requiring elective orthodontic treatment, $4.2 \%$ had DAl scores of 31-35 with severe malocclusion requiring highly desirable orthodontic treatment, and $0.5 \%$ had DAl scores $\geq 36$ with very severe/ handicapping malocclusion requiring mandatory orthodontic treatment. In the present study, the findings in children with DAl scores $\leq 25$ correlated with the results of the National Oral Health Survey and Fluoride Mapping, India ${ }^{8}$ and Nelson et al..$^{40}$ For DAl scores of $26-30$, the results of the current study correlate with those of the National Oral Health Survey and Fluoride Mapping, ${ }^{8}$ Nelson et al, ${ }^{40}$ Abdullah and Rock, ${ }^{41}$ and Onyeaso and Aderinokun. ${ }^{42}$ Lesser prevalence of DAl scores $\leq$ 25 has been observed in several studies. ${ }^{2,17,21,41}$ The reason for this difference in DAl scores could be due to inherited differences in tooth size and arch size since DAl includes measurements of the most relevant orthodontic traits (such as crowding) that affect dental aesthetics.

DAl score distribution and type of residence In the present study, the mean DAl score for children in urban areas was $20.5 \pm 5.5$ while the mean score for children in rural areas was $19.3 \pm 4.8$, a statistically significant difference $\left(Z=4.26,{ }^{* * *} \mathrm{P}:<.001, \mathrm{~S}\right)$. However, in a study by Otuyemi et al,28 the mean DAl score for children in urban areas was $22.57 \pm 6.56$ and the mean DAI score for children in rural areas was $22.1 \pm 4.9$, while the study by Ansai et al ${ }^{5}$ showed a mean DAI score of $29.5 \pm 0.53$ (SE) for children in urban areas and a mean DAI score of $31.5 \pm 0.61$ (SE) for children in rural areas. This difference may be attributed to differences in region, geographical location, and gender.

\section{CONCLUSIONS}

This study demonstrated that 1438 (79.9\%) of 1800 school children had little or no malocclusion requiring no or little orthodontic treatment. A total of $362(20.1 \%)$ school children had definite malocclusion requiring definite orthodontic treatment. 
Malocclusion is not a single entity but rather a collection of situations, each in itself constituting a problem, and any of these situations can be complicated by a multitude of genetic and environmental causes. The DAl is a relatively simple, reproducible, and valid index that can be used as a practical tool for epidemiologists and other dental personnel for screening children for orthodontic treatment need and also to assess the prevalence of malocclusion categories. The DAl appears to be the easiest tool to use, but it does not take into account buccal crossbite, posterior open bite, central line discrepancies, or a deep overbite, factors which may have considerable impact on treatment complexity and, therefore, weaken the index.

\section{REFERENCES}

1. Onyeaso CO, Sanu 00. Perception of personal dental appearance in Nigerian adolescents. Am J Orthod Dentofacial Orthop 2005;127:700-706.

2. Sureshbabu AM, Chandu GN, Shafiulla MD. Prevalence of malocclusion and orthodontic treatment needs among 13to 15-year-old school children of Davangere city, Karnataka, India. J Indian Assoc Public Health Dent 2005;6:32-35.

3. Houston WJB. Chapter 6. Walther's Orthodontic Notes. $4^{\text {th }}$ edition. The Stonebridge Publishers. 2000:46-50.

4. Klages U, Bruckner A, Zentner A. Dental aesthetics, selfawareness, and oral health-related quality of life in young adults. Eur J Orthod 2004;26:507-514.

5. Ansai T, Miyazaki H, Katoh Y, Yamashita Y, Takehara T, Jenny J, Cons NC. Prevalence of malocclusion in high school students in Japan according to the Dental Aesthetic Index. Community Dent Oral Epidemiol 1993;21:303-305.

6. McLain JB, Proffitt WR. Oral health status: Prevalence of malocclusion. J Dent Edu 1985;49:386-397.

7. Mitchell L, Carter NE, Doubleday B. Chapter 1. An Introduction to Orthodontics. $2^{\text {nd }}$ edition. Oxford University Press; 2001:5-10.

8. National Oral Health Survey and Fluoride Mapping (India), 2002-2003. Dental Council of India, Ministry of Health and Family Welfare, Govt. of India, New Delhi, 2004.

9. Abu Alhaija ES, Al-Nimri KS, Al-Khateeb SN. Self-perception of malocclusion among north Jordanian school children. Eur J Orthod 2005;27:292-295.

10. Soh J, Sandham A. Orthodontic treatment need in Asian adult males. Angle Orthod 2004;74:769-773.

11. Downer MC. Craniofacial anomalies-are they a public health problem? Int Dent $J$ 1987;37:193-196.
12. Cons NC, Jenny J, Kohout FJ, Songpaisan Y, Jotikastira D. Utility of the dental aesthetic index in industrialized and developing countries. J Public Health Dent 1989;49:163-166.

13. World Health Organization. Chapter 5. Oral Health Survey, Basic Methods. $4^{\text {th }}$ edition, AITBS Publishers and Distributors, New Delhi, India; 1999:47-51.

14. Jenny J, Cons NC. Establishing malocclusion severity levels on the Dental Aesthetic Index (DAl) scale. Aust Dent $J$ 1996;41:43-46.

15. Keay PA, Freer TJ, Basford KE. Orthodontic treatment need and the Dental Aesthetic Index. Aust Orthod J 1993;13:4-7.

16. Onyeaso $\mathrm{CO}$. An assessment of relationship between selfesteem, orthodontic concern, and Dental Aesthetic Index (DAl) scores among secondary school students in Ibadan, Nigeria. Int Dent $J$ 2003;53:79-84.

17. Otuyemi OD, Noar JH. A comparison between DAl and SCAN in estimating orthodontic treatment need. Int Dent $J$ 1996;46:35-40.

18. Cons NC, Jenny J, Kohout FJ, Jakobsen J, Shi Y, Ying WH, Pakalns G. Comparing ethnic group-specific DAl equations with the standard DAI. Int Dent $J$ 1994;44:153-158.

19. Onyeaso CO, BeGole EA. Orthodontic treatment need in an accredited graduate orthodontic center in North America: A pilot study. J Contemp Dent Pract 2006;7:87-94.

20. Beglin FM, Firestone AR, Vig KW, Beck FM, Kuthy RA, Wade D. A comparison of reliability and validity of 3 occlusal indexes of orthodontic treatment need. Am J Orthod Dentofacial Orthop 2001;120:240-246.

21. Chi J, Johnson M, Harkness M. Age changes in orthodontic treatment need: a longitudinal study of 10- and 13-yearold children, using the Dental Aesthetic Index. Aust Orthod $J$ 2000;16:150-156.

22. Onyeaso CO. Orthodontic treatment need of Nigerian outpatients assessed with the Dental Aesthetic Index. Aust Orthod $J$ 2004;20:19-23.

23. Jenny J, Cons NC, Kohout FJ, Jakobsen J. Difference in need for orthodontic treatment between Native Americans and the general population based on DAl scores. $J$ Public Health Dent 1991;51:234-238.

24. Johnson M, Harkness M. Prevalence of malocclusion and orthodontic treatment need in 10-year-old New Zealand children. Aust Orthod J 2000;16:1-8.

25. Esa R, Razak IA, Allister JH. Epidemiology of malocclusion and orthodontic treatment need of 12-13-year-old Malaysian schoolchildren. Community Dent Health 2001;18:31-36.

26. Rao DB, Hegde AM, Munshi AK. Malocclusion and orthodontic treatment need of handicapped individuals in South Canara, India. Int Dent J 2003;53:13-18.

27. Proffit WR. Chapter 4. Contemporary Orthodontics. 3rd edition, Harcourt (India) Private Limited, New Delhi, India; 2001:102-108. 
28. Otuyemi OD, Ogunyinka A, Dosumu O, Cons NC, Jenny J. Malocclusion and orthodontic treatment need of secondary school students in Nigeria according to the dental aesthetic index (DAI). Int Dent $J$ 1999;49:203-210.

29. Baca-Garcia A, Bravo M, Baca P, Baca A, Junco P. Malocclusions and orthodontic treatment needs in a group of Spanish adolescents using the Dental Aesthetic Index. Int Dent J 2004;54:138-142.

30. Thilander B, Pena L, Infante C, Parada SS, de Mayorga C. Prevalence of malocclusion and orthodontic treatment need in children and adolescents in Bogota, Colombia. An epidemiological study related to different stages of dental development. Eur J Orthod 2001;23:153-167.

31. Moyers RE. Chapters 6, 7, 17. Handbook of Orthodontics. $4^{\text {th }}$ edition, Year Book Medical Publishers, Inc., Chicago, Illinois; 1988:125-474.

32. Guaba K, Ashima G, Tewari A, Utreja A. Prevalence of malocclusion and abnormal oral habits in North Indian rural children. J Indian Soc Pedod Prev Dent 1998;16:26-30.

33. Steigman S, Weissberg Y. Spaced dentition. An epidemiologic study. Angle Orthod 1985;55:167-176.

34. Brunelle JA, Bhat M, Lipton JA. Prevalence and distribution of selected occlusal characteristics in the US population, 1988-1991. J Dent Res 1996;75:706-713.

35. al-Emran S, Wisth PJ, Böe OE. Prevalence of malocclusion and need for orthodontic treatment in Saudi Arabia. Community Dent Oral Epidemiol 1990;18:253-255.

36. Harrison RL, Davis DW. Dental malocclusion in native children of British Columbia, Canada. Community Dent Oral Epidemiol 1996;24:217-221.

37. Burden DJ, Pine CM, Burnside G. Modified IOTN: An orthodontic treatment need index for use in oral health surveys. Community Dent Oral Epidemiol 2001;29:220-225.

38. Hill PA. The prevalence and severity of malocclusion and the need for orthodontic treatment in 9-, 12-, and 15-yearold Glasgow schoolchildren. Br J Orthod 1992;19:87-96.

39. Nganga PM, Ohito F, Ogaard B, Valderhaug J. The prevalence of malocclusion in 13- to 15-year-old children in Nairobi, Kenya. Acta Odontol Scand 1996;54:126-130.

40. Nelson S, Armogan V, Abel Y, Broadbent BH, Hans M. Disparity in orthodontic utilization and treatment need among high school students. J Public Health Dent 2004;64:26-30.

41. Abdullah MS, Rock WP. Assessment of orthodontic treatment need in 5,112 Malaysian children using the IOTN and DAl indices. Community Dent Health 2001;18:242-248.

42. Onyeaso CO, Aderinokun GA. The relationship between Dental Aesthetic Index (DAI) and perceptions of aesthetics, function and speech amongst secondary school children in Ibadan, Nigeria. Int J Paediatr Dent 2003;13:336-341. 